\title{
Aplikasi Android Solenoid Door Lock Android Studi Kasus: Indekos Putri Griya Aluya
}

\author{
Wisnu Wendanto ${ }^{* 1}$, Haryo Basuki ${ }^{2}$, Yulianto Permadi ${ }^{3}$ \\ 1,2,3 Program Studi Sistem Komputer, STMIK AUB, Surakarta, Indonesia \\ e-mail: *1wendanto@stmik-aub.ac.id, ${ }^{2}$ haryo.basuki@stmik-aub.ac.id, \\ 3yuliantopermadi96@gmail.com
}

\begin{abstract}
Abstrak
Pintu merupakan akses utama untuk memasuki sebuah ruangan atau kamar, efesien si dan kenyamanan dalam penggunaan pintu pula sangat dibutuhkan untuk mempermudah manusia dalam mengakses sebuah ruangan terutama pada saat membawa banyak barang ataupun aktifitas lain yang menyulitkan untuk menggunakan kunci konvensional.

Di Indekos Putri Griya Aluya terdapat dua puluh delapan kamar yang semuanya masih menggunakan kunci konvensional. Karena penggunaan pada anak kunci sering diputar lama kelamaan anak kunci akan rusak karena gerigi pada anak kunci gundul, sehingga pintu tidak dapat dibuka dan terkadang pengguna kamar indekos setelah pulang dari kampung halaman anak kunci tertinggal. Untuk mempermudah pengguna kamar dalam mengakses kamar maka dibuatkan aplikasi android solenoid door lock sehingga pengguna dapat membuka dan mengunci kamar menggunakan smartphone android.

Hasil perancangan aplikasi ini menggunakan metode prototype. Sedangkan untuk menggambarkan alur diagram menggunakan flowchart sistem. Menggunakan aplikasi android studio dan arduino ide dalam pembuatan aplikasi, serta esp32 sebagai mikrokontroler dan solenoid door lock sebagai pembuka dan pengunci. Berdasarkan pengujian yang telah dilakukan menggunakan pintu replika, alat yang sudah dirancang dapat membantu masalah yang dihadapi pada indekos Putri Griya Aluya.
\end{abstract}

Kata kunci-Indekos Putri Griya Aluya, Solenoid Door Lock, Android Studio, Arduino IDE, ESP32

\footnotetext{
Abstract

Door is the main access to enter a roomor rooms, efficiency and comfort in the use of the door is also needed to facilitate people in accessing a room especially when carrying a lot of goods or activities Others that make it difficult to use conventional keys.

In Indekos Putri Griya Aluya There are twenty eight rooms that are all still using conventional keys. Because the use of the key children often played long time, the key child will be damaged because the cleats in the key child is bald, so that the door can not be opened and sometimes the room users are boarded after returning from the hometown of the key Child Left behind. To facilitate the room user in accessing the room then the application is created solenoid door lock Android So the user can open and lock the room using an Android smartphone.

The design results of this application using prototype method. As for describing the diagram flow using the system flowchart. Use Android Studio apps and Arduino ideas in app creation, as well as the ESP32 as a microcontroller and solenoid door lock as an opening and locking. Based on the tests that have been done using the replica doors, the tools that have been designed can help the problems faced at the boarding of Putri Griya Aluya.
} 
Keywords—Indekos Putri Griya Aluya, Solenoid Door Lock, Android Studio, Arduino IDE, ESP32

\section{PENDAHULUAN}

Pintu merupakan akses utama untuk memasuki sebuah ruangan, efesiensi dan kenyamanan dalam penggunaan pintu pula sangat dibutuhkan untuk mempermudah manusia dalam mengakses sebuah ruangan terutama pada saat membawa banyak barang ataupun aktifitas lain yang menyulitkan untuk menggunakan kunci konvensional. Seiring dengan kemajuan teknologi yang ada, masyarakat masih banyak menggunakan kunci pintu konvensional untuk membuka dan menutup pintu. Oleh karena itu dibutuhkan sebuah alat yang dapat membantu manusia dalam mengakses sebuah ruangan secara efisien dan modern.

Dalam kehidupan masyarakat, istilah kunci pintu konvensional atau kunci tuas sudah terasa begitu akrab, karena untuk media keamanan agar tidak sembarangan orang dapat masuk dan keluar pintu. Sementara itu dalam penggunaannya kunci konvensional terkadang mengalami kemacetan atau tidak dapat dibuka dan tidak jarang pula kunci konvensional dapat dibuka hanya dengan menggunakan seutas kawat ataupun dengan kunci tiruan lainnya.

Di Indekos Putri Griya Aluya terdapat dua puluh delapan kamar yang semuanya masih menggunakan kunci konvensional. Karena penggunaan kunci konvensional tersebut anak kunci sering diputar lama kelamaan anak kunci akan rusak karena gerigi pada anak kunci gundul, sehingga pintu tidak dapat dibuka. Dan tidak jarang pula pemilik kamar setelah pulang kampung, anak kunci tertinggal di kampung halaman. Informasi dari penjaga indekos bapak Ponilan Harsono, beliau memperbarui hingga lima belas anak kunci dalam kurun waktu dua tahun. Maka dari itu anak kunci yang rusak perlu diperbarui secara berkala atau rata - rata dua tahun sekali.

Untuk dapat mengatasi masalah anak kunci yang rusak maka diberikan solusi pembuatan aplikasi kunci menggunakan pattern berbasis Android. Aplikasi ini diusahakan menggunakan piranti seminimal mungkin agar spesifikasi dari ukuran sistem dapat diterapkan pada objek sesungguhnya. Sistem yang dirakit terdiri atas sebuah ESP32, Solenoid door lock, Mosfet IRF9540N, Buzzer sebagai alarm dan Adaptor Power Supply. Aplikasi Android Solenoid Door Lock ini menggunakan Solenoid door lock sebagai penggerak utama sehingga pintu dapat dikunci atau dibuka secara otomatis. Solenoid door lock akan dihubungkan dengan ESP32 yang kemudian dapat dikendalikan oleh Android. ESP32 sebagai pengendali utama yang mendapat masukan dari Android untuk mengendalikan Solenoid door lock. Display LCD (Liquid Crystal Display) Android akan menampilkan pattern sandi masukan, dan sebagai penampil saat ada penggantian password atau informasi status sistem. Pada alat ini juga dilengkapi dengan buzzer, fungsi buzzer itu sendiri sebagai penanda jika pengguna melakukan kesalahan dalam memasukan pattern tiga kali, buzzer secara otomatis berbunyi sebagai penanda bahwa ada kesalahan dalam memasukan pattern.

Mengacu pada hal-hal tersebut diatas, penulis berinisiatif membuat suatu perancangan aplikasi kunci menggunakan pattern agar dapat memberi keamanan yang lebih dan mengatasi masalah anak kunci yang gundul karena sering diputar untuk membuka induk kunci. Melihat hal tersebut, mendorong penulis melakukan penelitian dan selanjutnya di susun dalam skripsi yang berjudul "Aplikasi Android Solenoid Door Lock Indekos Putri Griya Aluya".

\section{METODE PENELITIAN}

\subsection{Metode Prototype}

Dalam perancangan Skripsi ini penulis menggunakan metode Prototype. Dengan Metode Prototype ini pengembang dan pengguna dapat saling berinteraksi selama proses pembuatan sistem. Sering terjadi seorang pengguna hanya mendefinisikan secara umum apa yang dibutuhkan, pemrosesan dan data - data apa saja yang dibutuhkan. Sebaliknya disisi 
pengembang kurang memperhatikan efesiensi algoritma. Kemampuan sistem operasi dan interface yang menghubungkan manusia dengan komputer. Proses pada prototype bisa dijelaskan sebagai berikut :

1. Pengumpulan kebutuhan : developer dan klien bertemu dan menentukan tujuan umum, kebutuhan yang diketahui dan gambaran bagian bagian yang akan dibutuhkan berikutnya. Detail kebutuhan mungkin tidak dibicarakan disini, pada awal pengumpulan kebutuhan.

2. Perancangan : perancangan dilakukan cepat dan rancangan mewakili aspek software yang diketahui. Dan rancangan ini menjadi dasar pembuatan prototype.

3. Evaluasai Prototype : klien mengevaluasi prototype yang dibuat dan dipergunakan untuk memperjelas kebutuhan software

\subsection{Analisis Sistem}

Pintu kamar yang ada sekarang menggunakan kunci pintu konvensional. Kunci pintu konvensional dalam penggunaannya terkadang mengalami kemacetan atau tidak dapat dibuka. Kunci pintu konvensional yang tidak dapat dibuka perlu penggantian secara berkala dan kemacetan kunci konvensional akan berakibat pengguna tidak dapat membuka pintu sehingga penulis akan merancang sebuah alat yang lebih efisien untuk membuka dan mengunci sebuah pintu. Alat yang dirancang ini akan bekerja saat bluetooth smartphone dihubungkan dengan bluetooth ESP32 jika sudah terhubung maka akan muncul tampilan permintaan set pattern baru, jika inputan pattern benar ESP32 akan menerima nilai 3 maka ESP32 akan memerintahkan solenoid door lock untuk membuka Kunci, jika ESP32 menerima nilai 2 maka ESP32 akan memerintahkan solenoid door lock untuk menutup kunci, jika terjadi kesalahan input pattern tiga kali ESP32 akan menerima nilai 4 maka ESP32 akan memerintahkan buzzer untuk berbunyi selama 1,5 detik tiga kali, dan jika pengguna lupa pattern yang sebelumnya maka pengguna dapat penggunakan fitur reset pattern yang ada pada aplikasi untuk mereset pola melalui SMS(Short Message Service). Sehingga dengan adanya alat yang dapat membuka dan mengunci pintu ini diharapkan semua pengguna dapat membuka dan mengunci pintu tanpa adanya kemacetan.

\subsubsection{Flowchart sistem yang sedang berjalan}

Flowchart sistem yang sedang berjalan menjelaskan alur penggunaan anak kunci yang digunakan untuk membuka pintu kamar. Berikut adalah Gambar 1 flowchart yang sedang berjalan di Indekos Putri Griya Aluya.

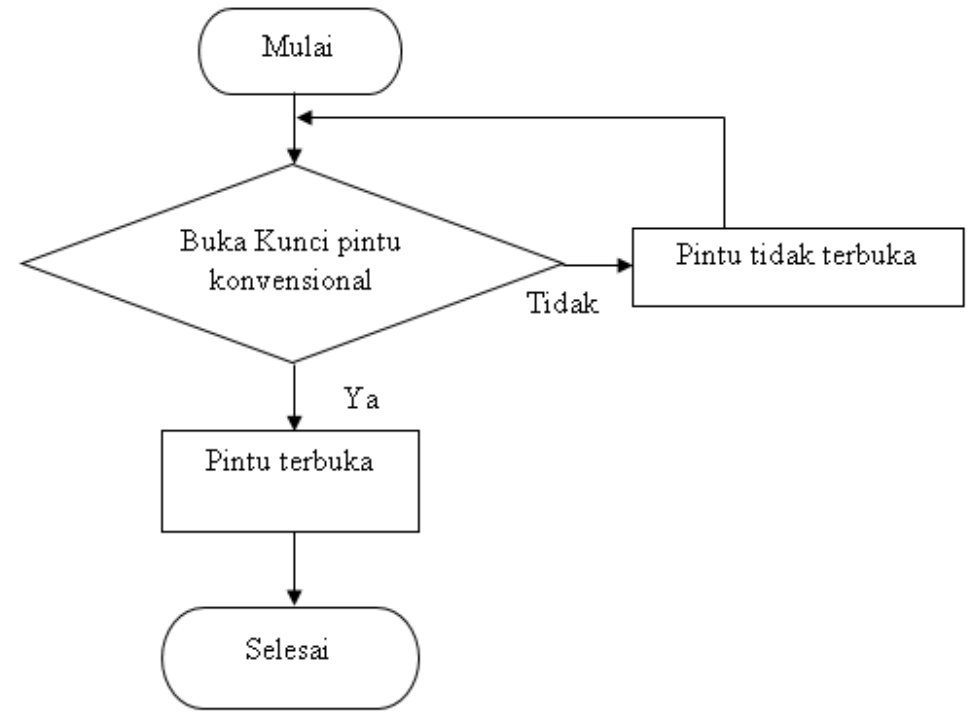

Gambar 1 Flowchart sistem yang berjalan

\subsubsection{Diagram Blok}

GO INFOTECH: JURNAL ILMIAH STMIKAUB Vol. 26, No. 2, Desember 2020: 174-185 


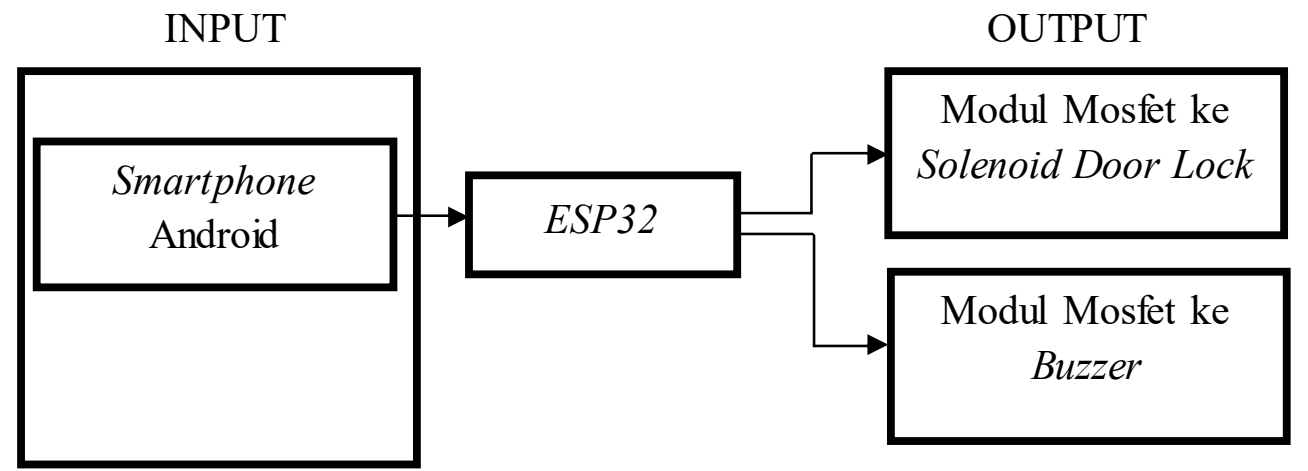

Gambar 2 Diagram blok

Proses dari diagram yaitu dimulai dari blok input yang menggunakan Aplikasi Android untuk menghubungkan bluetooth dari Smartphone Android ke Bluetooth ESP32 dan Aplikasi Android mengubahnya menjadi nilai elektronika kemudian mengirimkan nilai tersebut ke ESP32, setelah menerima nilai tersebut kemudian ESP32 akan membedakannya antara nilai $H I G H$ atau $L O W$, setelah ESP32 menerima input bernilai kunci $=H I G H$ maka ESP32 akan mengirimkan arus listrik melalui modul mosfet dan memerintahkan Solenoid Door Lock untuk membuka kunci, jika ESP32 menerima input bernilai kunci $=L O W$ maka ESP32 akan mengirimkan arus listrik melalui modul mosfet dan memerintahkan Solenoid Door Lock untuk menutup kunci, jika ESP32 menerima input bernilai buzz $=H I G H$ maka ESP32 akan mengirimkan arus listrik melalui modul mosfet dan memerintahkan Buzzer untuk berbunyi tiga kali dengan durasi masing - masing 1,5 detik lalu berhenti. Berdasarkan gambar diatas maka dapat diuraikan fungsi dari masing-masing blok yaitu:

1. Smartphone Android

Smartphone Android sebagai otak dari sistem, data input dari pengguna dan Nilai diproses oleh ESP32 yang hasilnya outputnya akan diumpankan ke modul mosfet dan modul mosfet mengirimkan arus tegangan ke Solenoid Door Lock dan Buzzer.

2. $\quad E S P 32$

ESP32 dalam rangkaian ini digunakan sebagai pemroses data masukan dari Smartphone Android untuk mengirimkan data HIGH atau LOW ke Solenoid Door Lock dan Buzzer.

3. Solenoid Door Lock dan Buzzer

Dalam rangkaian ini digunakan sebagai output pada alat ini digunakan untuk membuka dan mengunci pintu serta menghidupkan Alarm.

\subsubsection{Flowchart Sistem Yang Dibangun}

Berikut adalah Gambar 3 Flowchart sistem yang dibangun pada Aplikasi Android Solenoid Door Lock Indekos Putri Griya Aluya : 


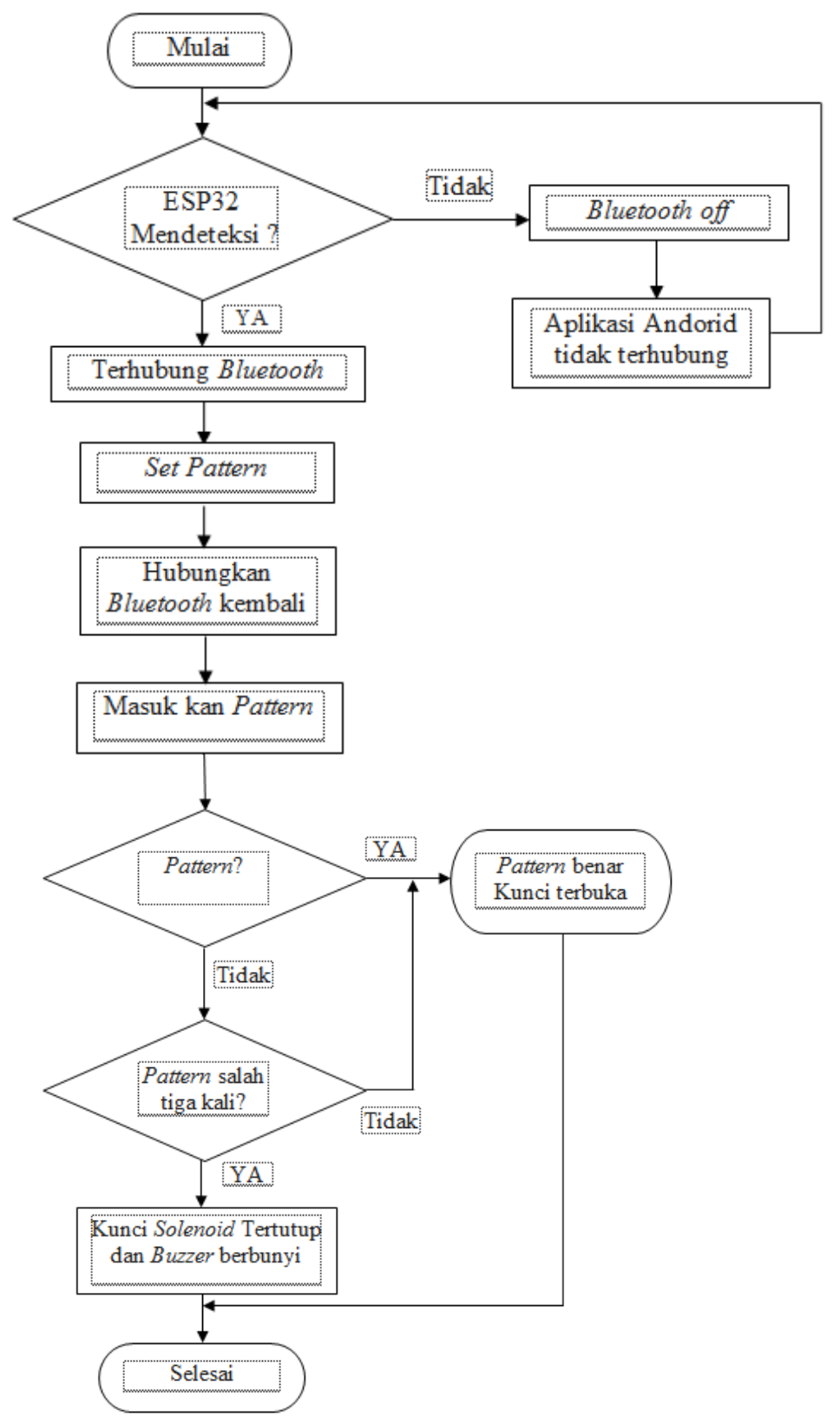

Gambar 3 flowchart sistem yang dibangun

Penjelasan Flowchart berikut :

a. Jika Bluetooth Smartphone tersambung dengan ESP32, maka aplikasi Door Lock dapat dihubungkan dengan ESP32 jika tidak dapat terhubung maka tidak dapat berkomunikasi.

b. Jika sudah terhubung di aplikasi dihalaman pertama akan muncul Set Pattern.

c. Jika sudah Set Pattern maka harus menghubungkan ke bluetooth kembali dan akan muncul tampilan pattern,

d. Jika masukan pattern benar maka solenoid akan terbuka, dan jika salah sampai tiga kali, buzzer akan berbunyi. 


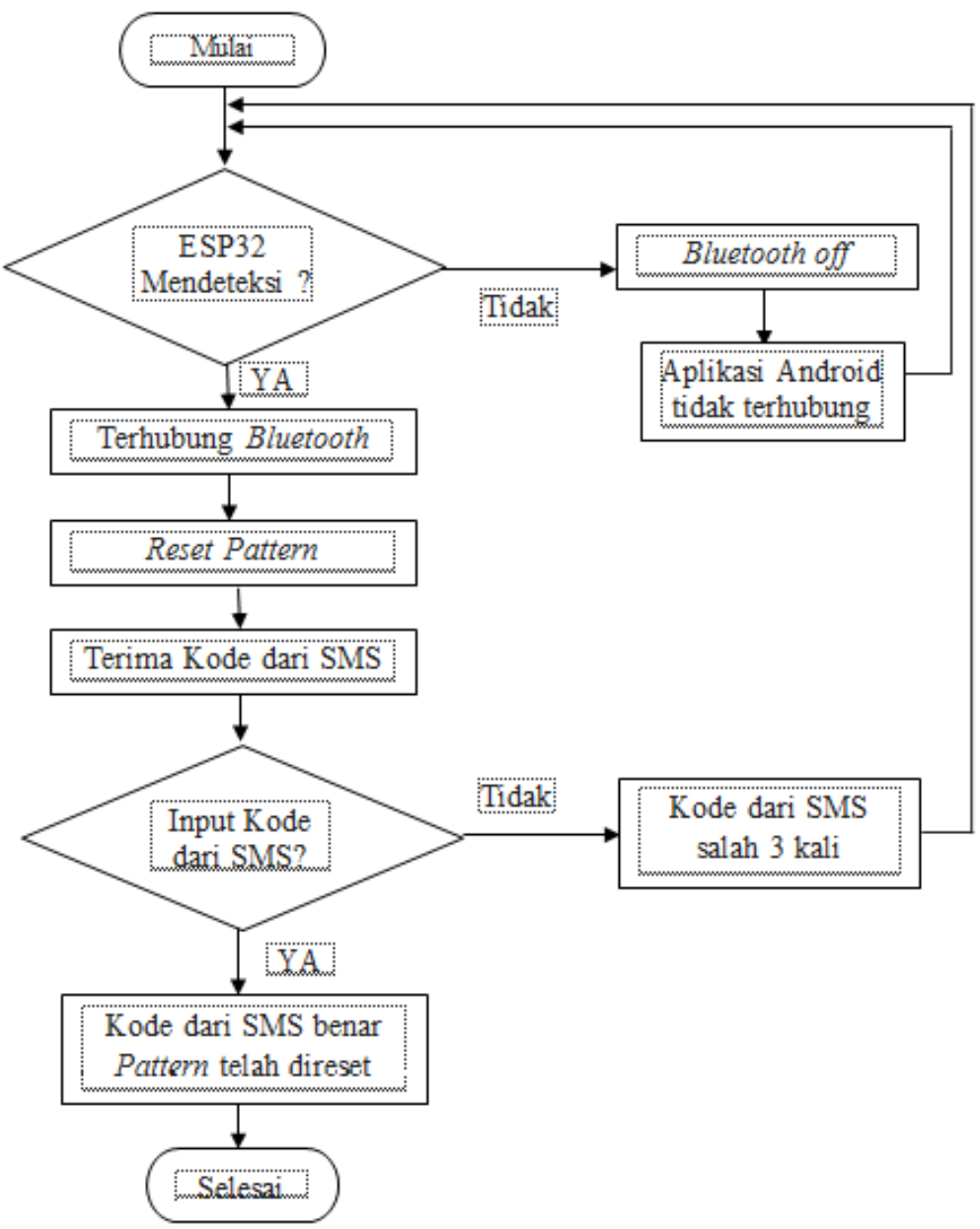

Gambar 4 flowchart sistem yang akan dibangun

Penjelasan Flowchart berikut :

a. Jika Bluetooth Smartphone tersambung dengan ESP32, maka aplikasi Android Solenoid Door Lock dapat dihubungkan dengan ESP32 jika tidak dapat terhubung maka tidak dapat berkomunikasi.

b. Pada saat bluetooth sudah terhubung dan pengguna ingin mereset pattern. Maka pengguna hanya perlu menekan button reset pattern pada halaman awal aplikasi.

c. Setelah menekan button reset pattern maka akan muncul notifik asi SMS yang berisikan kode pasword untuk di inputkan di aplikasi agar pattern dapat direset. Jika pengguna salah dalam menginput kode SMS sampai tiga kali maka aplikasi akan kembali ke menu utama.

\section{HASIL DAN PEMBAHASAN}

\subsubsection{Tahap untuk membuka dan mengunci}

Pada tahap pertama perlu untuk Menghubungkan bluetooth terlebih dahulu dengan smartphone android ke bluetooth ESP32 yang ada pada pintu. Jika bluetooth tidak dapat terhubung maka aplikasi tidak akan dapat berkomunikasi dengan Solenoid Door Lock dan ESP32. 


door_lock $\quad \vdots$

Paired Devices

RESET KEY

PAIRED DEVICES

Gambar 5 Door lock

Pada menu ini klik button PAIRED DEVICES untuk menghubungkan bluetooth smartphone dengan bluetooth kamar satu.

1. Jika pilihan menu bluetooth sudah muncul pilih bluetooth kamar satu. Jika memilih bluetooth yang lain maka aplikasi tidak akan dapat berkomunikasi dengan ESP32.

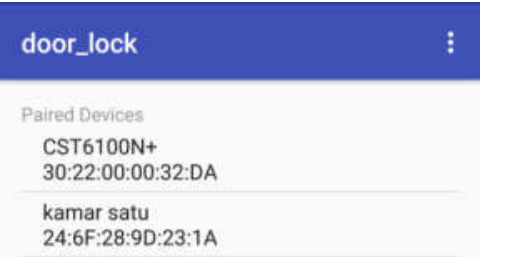

RESET KEY

PAIRED DEVICES

Gambar 7 menu bluetooth

2. Pada menu ini klik menu kamar satu untuk menghubungkan bluetooth smartphone dengan bluetooth yang ada di kamar satu. Jika pada saat bluetooth kamar satu sedang dalam keadaan off maka bluetooth tidak akan terhubung.

a. Masukan set pattern sesuai keinginan. 


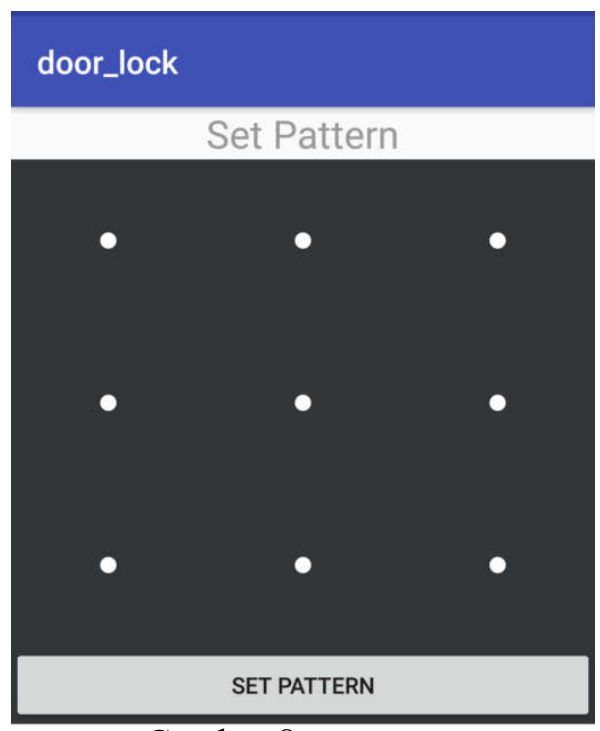

Gambar 8 set pattern

Pada menu ini set pattern atau artinya membuat pattern untuk pertama kali yang seterusnya akan digunakan untuk membuka kunci Solenoid Door Lock sampai pattern direset kembali.

b. Masukkan pattern sesuai dengan pattern yang sudah di set sebelumnya.

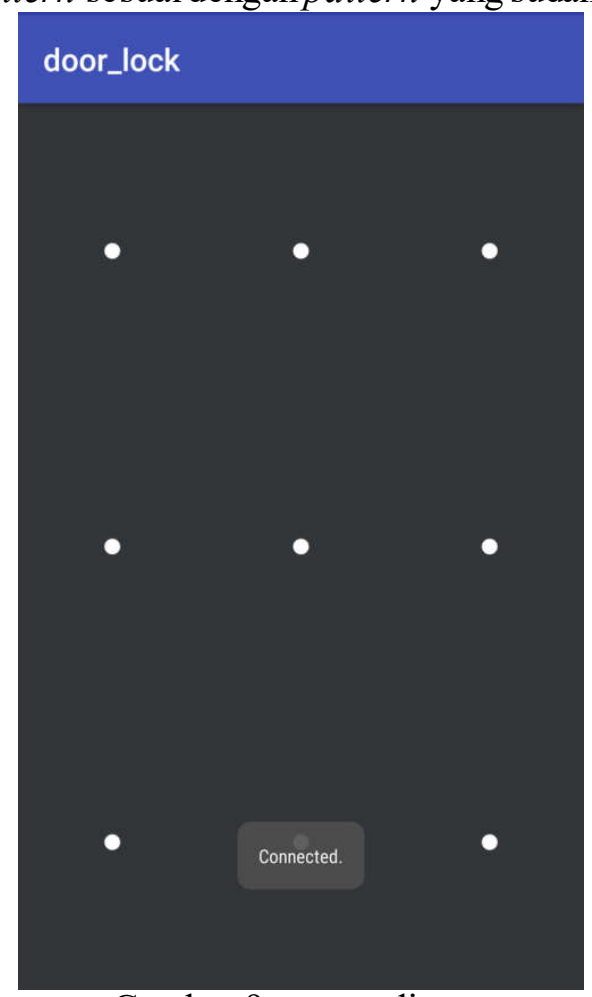

Gambar 9 pattern direset

Pada menu ini kondisi Solenoid dalam keadaan terkunci dan diperlukan pattern untuk membuka kunci Solenoid Door Lock.

c. Kondisi saat pattern salah memasukan pola satu kali 


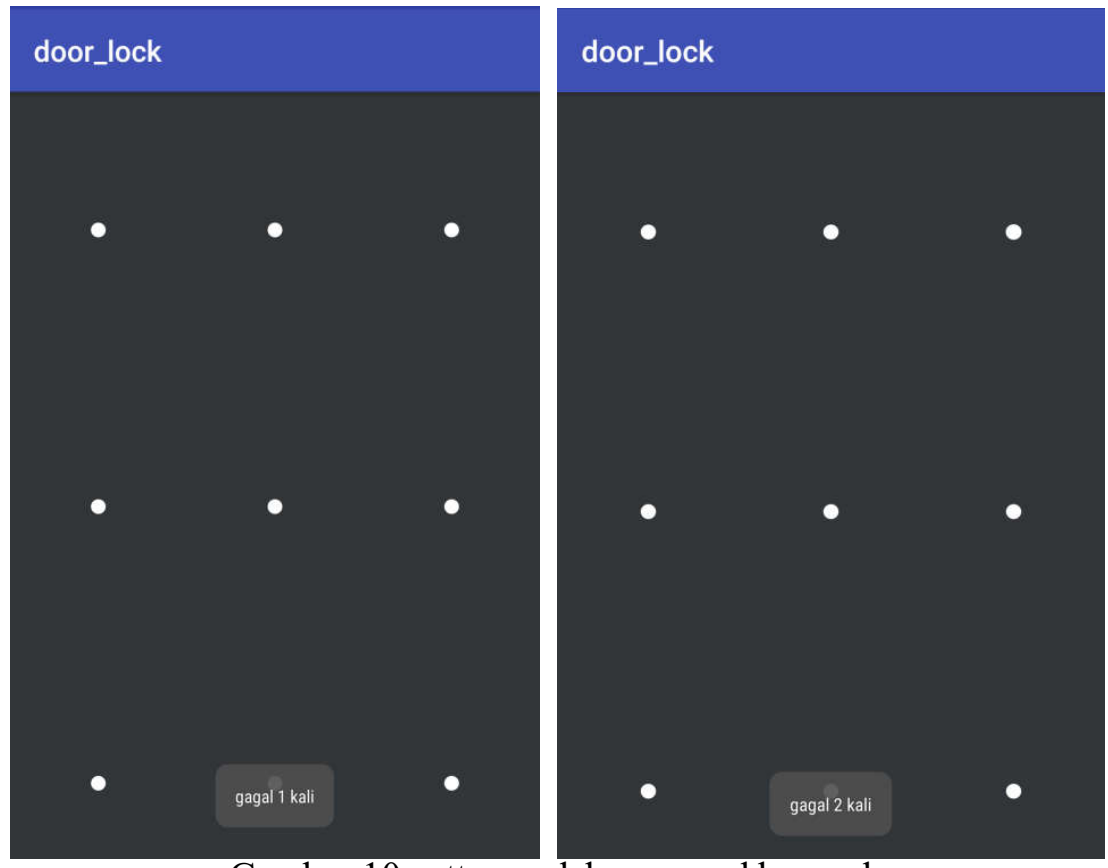

Gambar 10 pattern salah memasukkan pola

d. Kondisi saat pattern salah memasukan pola tiga kali dan buzzer akan berbunyi.

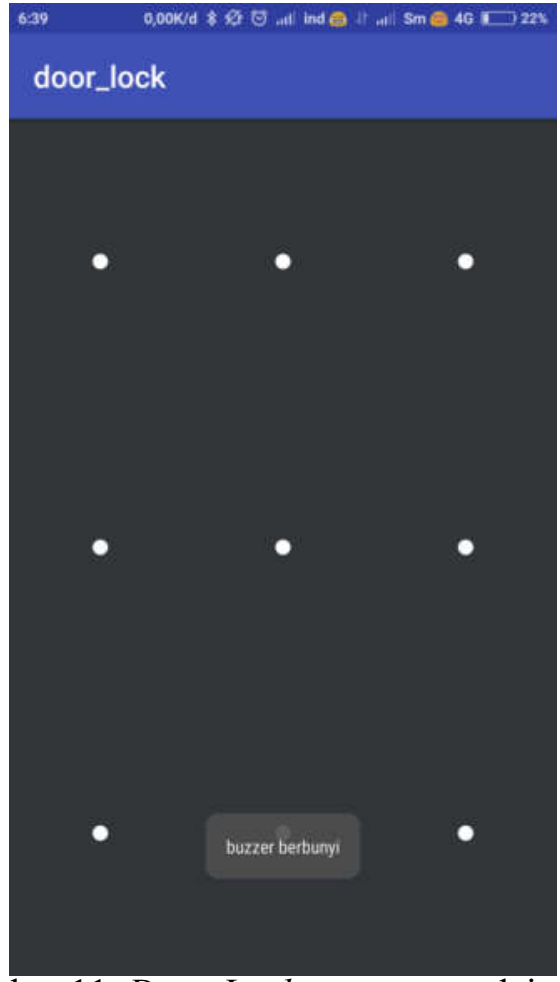

Gambar 11. Door Lock pattern gagal tiga kali

Pada menu ini pengguna salah memasukan pattern sampai tiga kali sehingga buzzer akan berbunyi beep tiga kali dengan durasi masing-masing 1,5 detik.

e. Kondisi saat aplikasi Solenoid Door Lock terbuka 


\section{door_lock}

PINTU TERBUKA

KUNCI PINTU

RESET PATTERN DAN KUNCI

Gambar 12 Solenoid Door Lock terbuka

Pada menu ini menandakan bahwa kunci solenoid pada pintu sedang dalam keadaan terbuka.

\subsubsection{Tahap untuk mereset pattern}

Pada tahap pertama perlu untuk Menghubungkan bluetooth terlebih dahulu dengan smartphone android ke bluetooth ESP32 yang ada pada pintu. Jika bluetooth tidak dapat terhubung maka aplikasi tidak akan dapat berkomunikasi dengan Solenoid Door Lock dan ESP32.

1. Jika pilihan menu bluetooth sudah muncul pilih bluetooth kamar satu. Jika memilih bluetooth yang lain maka aplikasi tidak akan dapat berkomunikasi dengan ESP32.

\begin{tabular}{l} 
door_lock \\
\hline Paired Devices \\
CST6100N+ \\
30:22:00:00:32:DA \\
kamar satu \\
24:6F:28:9D:23:1A
\end{tabular}

\section{RESET KEY}

PAIRED DEVICES

Gambar 13 reset key

Pada menu ini klik menu kamar satu untuk menghubungkan bluetooth smartphone dengan bluetooth yang ada dikamar satu. Setelah bluetooth terhubung maka pilih button RESET KEY. Maka kode pasword dari SMS akan dikirimkan ke destinasi nomor tujuan. Setelah kode pasword diterima lalu dimasukan sepertigambar dibawah agar pattern dapat direset. 


\section{door_lock}

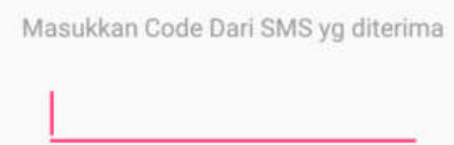

RESET PATTERN

Message Sent successfully!

Gambar 14 reset pattern kode pasword via SMS

Pada menu ini pengguna akan menginputkan kode pasword dari SMS untuk mereset pattern yang sebelumnya.

\section{KESIMPULAN}

Berdasarkan dari hasil perancangan dan pengujian alat, maka dapat ditarik kesimpulan sebagai berikut :

1. Dari hasil perancangan dan implementasi Aplikasi Android Solenoid DoorLock Pattern yang dibuat menggunakan alat ESP32, Solenoid Door Lock, dan Aplikasi Android Studio ini mampu membuka dan mengunci pintu secara otomatis dengan Aplikasi Android.

2. Pengguna bisa lebih menghemat pengeluaran biaya dikarenakan penggantian anak kunci secara berkala.

3. Pengguna bisa lebih mudah dalam penggunaan karena kunci dapat terbuka dengan konektivitas bluetooth dengan jarak maksimal deteksi 0-10 meter tanpa terhalang dinding.

\section{SARAN}

Aplikasi Android Solenoid Door Lock ini masih dapat dikembangkan lebih lanjut, dengan harapan:

1. Untuk pengembangan lebih lanjut Aplikasi Android Solenoid Door Lock dapat menggunakan tambahan sumber daya listrik dari baterry yang lebih canggih jika listrik padam alat tetap dapat bekerja.

2. Ditambahkan kamera CCTV untuk memantau keadaan didepan pintu.

3. Menggunakan sensor suara yang sensitif dan peka untuk mendeteksi suara untuk membuka dan mengunci pintu.

4. Menggunakan sensor deteksi panas. 


\section{DAFTAR PUSTAKA}

[1] Sri Setyani. 2017. Rancang Bangun Alat Pengaman Brankas Menggunakan Rfid (Radio Frequency Identification) dengan memanfaatkan E-KTP Sebagai Tag Berbasis Arduino. Jurnal Unnes, November. Program Studi Teknik Elektro Fakultas Teknik, Universitas Negeri Semarang

[2] Benedictus Surya Artha Mahendra. 2018. Kunci Pintu Pintar Berbasis RFID dan Biometri dengan Sistem Pengamanan Kamera. Jurnal USD, November. Program Studi Teknik Elektro Fakultas Sains dan Teknologi, Universitas Sanata Dharma Yogyakarta.

[3] Deni Adi Setiawan. 2019. Prototype Home Security System dengan Autentifikasi KTPEl. Jurnal UNY, Februari. Program Studi Teknik Elektronika, Fakultas Teknik Universitas Negeri Yogyakarta.

[4] Arifianto, Teguh. 2011. Membuat Interface Aplikasi Android Lebih Keren dengan LWUIT. Yogyakarta: Andi Publisher.

[5] Hermawan S, Stephanus. 2011.Mudah membuat Aplikasi Android. Yogyakarta :Andi Offset.

[6] Nazarudin Safaat Harahap. 2012. Pemograman Aplikasi Mobile Smartphone dan Tablet PC Berbasis Android. Informatika. Bandung.

[7] www.developer.android.com

[8] Biswas, Shatadru Bipasha, dan M. Tariq Iqbal. 2018. "Solar Water Pumping System Control Using a Low Cost ESP32 Microcontroller." 2018 IEEE Canadian Conference on Electrical \& Computer Engineering (CCECE).

[9] Malvino, A.P. 1993. Electronic Principle. Singapore: McGraw-Hill.

[10] www.Arduino.cc 